\title{
La búsqueda del papel social del maestro
}

\author{
Alicia Téllez-Fajardo ${ }^{\star}$, Marlen María Nieves-Tavera ${ }^{\star *}$
}

* M.Sc. en Pedagogía y Evaluación Educativa. Investigadora externa del grupo "Pedagogía y Lenguajes" de la Universidad Cooperativa de Colombia, sede Bucaramanga. Investigadora externa del Grupo Pedagogía y Lenguajes..

\section{Correo electrónico:} aliciatellezfajardo@gmail.com

** Magíster en Investigación y Docencia. Docente, Universidad Cooperativa de Colombia, sede Bucaramanga. Investigadora del grupo "Pedagogía y Lenguajes" de la misma universidad.

Correo electrónico:

marlen.nieves@campusucc.edu.co

Recibido: 28 de agosto del 2013

Aprobado: 11 de noviembre del 2013

Cómo citar este artículo: Téllez-Fajardo, Alicia y Nieves-Tavera, Marlen María. "La búsqueda del papel social del maestro". Rastros Rostros 15.29 (2013): 83-92. Impreso.

\begin{abstract}
Resumen
Este artículo de reflexión es el resultado de más de diez años de estudios realizados en la Facultad de Educación de la Universidad Cooperativa de Colombia, sede Bucaramanga, por el grupo "Pedagogía y Lenguajes". El propósito del texto es hacer un recorrido por la historia de la formación de los maestros, desde los inicios en el Gobierno del general Santander, hasta finales del siglo $\mathrm{xx}$, mostrando la evolución que ha experimentado en los diferentes gobiernos, de acuerdo con su visión de la educación; naturalmente, enfatizando en la concepción del rol social del maestro. Este énfasis en la mirada del rol social obedece a la búsqueda de pistas para la formación de maestros con la capacidad de orientar políticas educativas centradas en la investigación, a fin de generar conocimiento y desarrollo creativo, sin descuidar la solidaridad, con el fin responder a las exigencias actuales. Se presentan ocho momentos históricos de la formación de los maestros en el país; actualmente se hacen esfuerzos para que en la formación de los docentes se mantenga lo investigativo, y lo pedagógico tenga la trascendencia correspondiente con la responsabilidad social que exige la sociedad.
\end{abstract}

Palabras clave: maestro, pedagogía, rol social, saber pedagógico.

\section{The Search for the Social Role of the Teacher}

\begin{abstract}
This article is the result of over ten years of studies conducted by the Pedagogy and Languages group in the Faculty of Education at the Bucaramanga campus of Universidad Cooperativa de Colombia. The aim of the text is to review the history of teacher training, from its beginnings during General Santander's government in the early $19^{\text {th }}$ century, until the end of the $20^{\text {th }}$ century. Its evolution is shown through different governments, according to their vision of education, and, naturally, emphasizing the idea of the teacher's social role. This focus on the social role arises out of the search for clues in the training of teachers with the ability to orient educational policies centered on research in order to generate knowledge and creative development, without neglecting solidarity, and with the end goal of meeting current requirements. Eight historical moments in the country's teacher training are presented. Currently, efforts are being made to maintain research as part of teacher training, and to ensure that the pedagogy is accorded an importance that matches the social responsibility demanded by society.
\end{abstract}

Keywords: teacher, pedagogy, social role, pedagogical knowledge.

\section{A busca do papel social do professor}

\section{Resumo}

Este artigo de reflexão é resultado de mais de dez anos de estudos realizados na Faculdade de Educação da Universidade Cooperativa da Colômbia, sede Bucaramanga, pelo grupo Pedagogia e Linguagem. O propósito do texto é fazer uma retomada da história da formação dos professores, desde o início do Governo do general Santander até o final do século xx, mostrando a evolução que experimentou nos diferentes governos, de acordo com sua visão de educação; naturalmente, enfatizando na concepção do papel social do professor. Essa ênfase no papel social obedece à busca de pistas para a formação de professores com capacidade de orientar políticas educativas centradas na pesquisa, com o objetivo de gerar conhecimento e desenvolvimento criativo, sem descuidar a solidariedade, a fim de responder às exigências atuais. São apresentados oito momentos históricos da formação dos professores no país; atualmente são feitos esforços para que, na formação dos docentes, mantenha-se a pesquisa e o pedagógico tenha a transcendência correspondente à responsabilidade social que exige a sociedade.

Palavras-chave: professor, pedagogia, papel social, saber pedagógico. 


\section{Introducción}

En América Latina [...] la cuestión más apremiante es la constitución de sujetos políticos. Si el análisis de la pérdida de identidades colectivas en nuestras sociedades es correcto, lo que se impone como tarea primordial es la reflexión sobre la desarticulación y rearticulación de los sujetos.

(Lechner 23)

Creemos que el conocimiento de la historia que ha recorrido un grupo social, en este caso, los maestros, se convierte en un instrumento válido en la búsqueda de sentidos sobre el papel social que este ha ejercido durante 205 años de independencia. Esta búsqueda de sentidos le permite a los maestros resignificar su papel $\mathrm{y}$ a las instituciones formadoras de maestros, orientar sus programas hacia el cumplimiento de sus misiones. En el caso de la Universidad Cooperativa de Colombia, esto se da en la formación de maestros con criterios políticos, creativos y solidarios.

El propósito de este texto es brindar algunos elementos para comprender la importancia que tiene el hecho de que el maestro (no el docente) ${ }^{1}$ sea un profesional con reconocimiento de su rol social. Para entender esta distinción se tiene en cuenta uno de los aportes logrados en el proceso de investigación del grupo encabezado por Olga Lucía Zuluaga, ${ }^{2}$ que plantea la distinción entre dos sujetos de la enseñanza:

\section{Existen dos sujetos de la enseñanza. Por una parte aquel que se relaciona con las ciencias o con los saberes a par- tir de un método, es decir, el maestro [...] por otra parte otro sujeto que también enseña y al que se llama docen- te. Este sujeto de la enseñanza es reconocido como tal, no a partir del método de enseñanza, sino del saber que transmite. (Zuluaga 49)}

Para el cumplimiento del citado propósito se presentan algunas travesías recorridas por los maestros como sujetos sociales, las cuales pueden tomarse como elementos para continuar la búsqueda.

1 La diferencia básica estriba en que el maestro es formador y el docente es el administrador de un currículo.

2 Por más de treinta años ha construido un campo conceptual y una historia de la pedagogía y de la práctica pedagógica en Colombia.

\section{Un viaje para reconocer al maestro en la historia}

En su artículo titulado El círculo del tiempo y los maestros, Patricia Calonje hace una excelente analogía entre una tribu nómada de Irán llamada los Baktiaritas y los maestros. La autora compara las costumbres de estos nómadas y la historia del maestro, tal como han sido definidos socialmente a partir de su oficio: la enseñanza. Calonje pertenece a ese gran grupo de maestros que busca salir del círculo y ubicarse en otro papel social, tan necesario hoy, que se necesita construir valores sociales para una sociedad en constantes transformaciones. Para comprender la analogía propuesta por la citada autora, se presenta la siguiente síntesis de las costumbres de la tribu de los Baktiaritas:

Todo en la vida de los Baktiaritas es inmemorial, o tan antiguo que no hay memoria cuando empezó [...] este pueblo se aferra a la tradición en la medida en que cada hijo desea ser como su padre, repetir sus realizaciones. No hay interrogantes en relación con el pasado, con su historia, con lo que fueron. Sólo interesa el presente y la circunstancia $[\ldots]$ es una vida sin cambios. Cada noche es el final de un día como el de ayer y cada mañana será el inicio de una jornada como la del día anterior. (Bronoswky 60-62)

Para situar puntos de encuentro en la analogía citada, Calonje afirma:

Así como los Baktiaritas, el maestro ha estado sumido en su pasividad, sin contacto con otros intelectuales, sin el reconocimiento de su condición como tal y sin la posibilidad de relacionarse con los desarrollos más importantes del pensamiento contemporáneo, ya sea en el ámbito de la ciencia, de la cultura, de los valores éticos y morales, de la filosofía y de la historia. Su formación no lo ha puesto en contacto con los problemas propios de su cultura y de su entorno, impidiendo el rescate de los valores culturales autóctonos y la búsqueda de sus raíces (14).

La citada autora agrega que los Baktiaritas viven en Irán, en un territorio ubicado en los montes Zagros, una cadena montañosa cercana al golfo Pérsico y situado al oeste de la ciudad de Ispahan; son nómadas desde hace diez mil años. Este vagar incesante a través de seis cordilleras, ascendiendo a veces hasta los cuatro mil metros de altura, y luego descendiendo al ardiente desierto, es el reto que deben enfrentar cada año. Así como los 
maestros que deben recorrer grandes distancias para llegar a su trabajo, o enfrentar situaciones que no cambian, como la influencia de los gamonales, alcaldes y politiqueros, que han buscado manejarlos, aprovechar su labor y desconocer su influencia en la construcción del tejido social y de la orientación en la sociedad.

Para precisar puntos de encuentro con esta analogía, el presente texto ha establecido seis momentos que han marcado el rol social del maestro, respetando otras clasificaciones igualmente válidas, ${ }^{3}$ y busca pistas para una nueva: un maestro con criterios políticos, creativos y solidarios, según la misión de la universidad.

\section{El inicio de la travesía: de la mano de Joseph Lancaster, un funcionario y apóstol vigilado}

Fue Francisco de Paula Santander, en 1821, que autorizó el establecimiento de las primeras Escuelas Normales en las principales ciudades de Colombia. En estas escuelas, al aprendiz de maestro se le trababa como a un niño, como lo afirma Herrera y Low: "Estas eran aún de carácter embrionario e inicialmente no se diferenciaban de las escuelas de primeras letras, pues en éstas se adiestraba al maestro de manera simultánea con los niños en los conocimientos que posteriormente habría de impartir" (42).

Estas escuelas, llamadas de Enseñanza mutua, recibían el nombre de Escuelas Normales y se limitaban a la difusión del método de enseñanza monitorial de Joseph Lancaster. En estas circunstancias, la imagen del maestro comienza en el país con una carga cultural, la cual le asignó un conjunto de roles que le dieron, en palabras de Álvarez, "la responsabilidad de apóstol pedagogo y funcionario". Un funcionario que debía responder ante la patria de la instrucción de la juventud, el cual debía ser poseedor de ciertas condiciones; así lo expresa Álvarez:

En cuanto al encargo, debía entender su labor como un destino, pues el destino estaría trazado y no habría lugar a desviaciones. Él mismo era parte de ese destino, su vida debía "reglarse" de acuerdo con las pautas de conducta que le impusieron. Además de ser un hombre capaz y de madura edad, debía ser de muy arreglada conducta y honrados procederes: paciente, constante, perseverante y de buena familia. Su vida: ejemplar y virtuosa, hombre recto,

\footnotetext{
3 Por ejemplo, las que presenta Pineda Martínez (54-68): maestro apóstol, sindicalista, asalariado, maestro artesano, maestro funcionario: la "tuerca de la máquina estatal", maestro taylorizado: administrador de procesos, intelectual subordinado, líder social, trabajador de la cultura, innovador de proyectos y experiencias, sujeto de saber y deseo de política, maestro expedicionario.
}

buen súbdito, excelente padre de familia. Su abnegación y absoluta consagración a la patria eran imprescindibles, se recomendaba que fuera casado y mayor de 18 años y no podía padecer enfermedad crónica o contagiosa (62).

¿Qué elementos importantes surgen en esta época en la imagen social del maestro? La cita anterior da algunos rasgos muy precisos que podrían resumirse en un ciudadano ejemplar que tenía la vigilancia de la sociedad y del Estado, un apóstol, pedagogo y funcionario. Zuluaga (267) afirma que para cuidar esta imagen se crearon estrategias como las Juntas curadoras, formadas por padres de familia y presididas por el jefe político, según un decreto del 3 de octubre de 1826.

Pero además de estas juntas, también el maestro era vigilado por los curas y por el mismo Estado, hasta llegar a extremos que Álvarez llama "patéticos", como se puede ver en el Decreto 595 de 1886 de la República de Colombia: "toda escuela debe componerse de dos funcionarios: el que enseña a los niños y el que inspecciona y dirige al maestro y hace efectivos el cumplimiento de los reglamentos y la asistencia de los alumnos" (15).

La característica reguladora en todo este periodo fue la vigilancia, lo cual permite agregarle al maestro el calificativo de vigilado. La vigilancia tenía un carácter sancionatorio grave y discriminatorio, como puede observarse con todo el peso en la siguiente cita, correspondiente a la Pastoral del Obispo de Pamplona:

A los padres de familia i a todos los católicos de la diócesis de Pamplona [...] El señor obispo de esta diócesis ha expedido en 17 de febrero último, una pastoral que concluye así: "En fuerza de las reflexiones anteriores, i estando Nos convencidos por hechos notorios, informes fidedignos i observaciones propias, que en los colejios de ambos sexos establecidos en Piedecuesta, perteneciente a nuestra diócesis i rejentados por el señor Victoriano Paredes i su esposa, se da a los jóvenes una educación relijiosa que no es conforme con los dogmas y preceptos de nuestra Santa Iglesia Romana, i que todos los superiores son protestantes, o por menos de mui dudosa catolicidad [...] en uso de nuestras facultades, i en cumplimiento de los deberes de nuestro ministerio, prohibimos a los padres de familia católicos, de nuestro obispado que pongan a sus hijos en dichos establecimientos". (41)

Podría decirse que la vigilancia se constituye en un elemento de coacción que le impone al maestro la condición de actuar no solo atendiendo a las exigencias del Estado, sino a las de la Iglesia Católica, que mantiene la estructura y el pensamiento colonial. 


\section{La institucionalización del saber pedagógico: el maestro como sujeto de un saber específico}

El saber pedagógico, en términos de Olga Lucía Zuluaga,

\begin{abstract}
acoge a un saber más amplio que incluye los diferentes métodos de enseñanza y la formación del hombre. De esto se deriva para los niños un trato más de comunicación que de orden, es permanente en contraposición a los procedimientos utilizados en la Enseñanza mutua bajo la vigencia de las normales del viejo "Manual del sistema de Enseñanza mutua”, de 1826 (110).
\end{abstract}

En 1845, la Dirección General de Instrucción Pública aprobó el programa de pedagogía desarrollado en un Manual del Profesor Primario, y específicamente la formación pedagógica de los alumnos de la Escuela Normal estaba contenida en cuatro manuales redactados por José María Triana:

1. Manual de Enseñanza Mutua para las escuelas de primeras letras. 2. Manual que deben tener presente en las escuelas para la enseñanza de la gramática castellana, según el método de Pestalozzi, estractado (sic) de sus obras. 3. Manual que contiene los diversos cursos en que se divide la enseñanza de la aritmética mental, según el método de Pestalozzi, i reglas que deben practicar los maestros para el buen uso de los cuadros. 4. Manual del Profesor Primario. (Zuluaga 110)

Olga Lucía Zuluaga considera que el Manual del profesor primario es un compendio acerca de los planteamientos de Pestalozzi y se convierte en la principal diferencia con la etapa anterior, por cinco saberes que llegan a configurar el saber del maestro, los cuales son: 1) Concepción de la pedagogía; 2) La educación del hombre por el desarrollo de sus facultades; 3 ) Concepción del método para lograr la instrucción; 4) El estatuto del maestro y 5) La reforma del Manual del sistema de enseñanza mutua, de 1826 (Zuluaga 113).

¿Qué elementos importantes surgen en esta época en la imagen social del maestro? Los acontecimientos pedagógicos de esta época y muy especialmente la reforma propiciada por Mariano Ospina y José María Triana, en 1844, le dieron al maestro el estatus de un sujeto de saber pedagógico. Este saber no aparece disperso en catecismos ni en textos para que el maestro los recoja; tampoco se ha confiado su reconocimiento a examinadores ajenos a la pedagogía; se da al maestro la posibilidad de ser sujeto de la práctica pedagógica y su saber aparece institucionalizado en la Escuela Normal.

Desde el comienzo, en las escuelas normales se trabajó con miras a lograr un currículo único, con la intencionalidad de formar ciudadanos que respondieran por sí mismos y por la orientación de los niños asignados a su cargo. Los ilustrados de la época, encabezados por Mariano Ospina Rodríguez, estaban convencidos de que la educación requería una profunda transformación, porque el país no necesitaba más médicos, sacerdotes y abogados, sino formación técnica.

Quienes orientaban la educación desde el Gobierno habían comprendido que era el momento para iniciar el proceso de desarrollo industrial. Ospina, en su plan de estudios y reforma educativa (Ley 21 de 1842), estableció el currículo para las universidades y puntualizó que los asuntos industriales, lo técnico y lo relacionado con la agricultura era lo prioritario y que se debía desestimular la formación en teología, en medicina y derecho, porque ya el país no necesitaba más personas formadas para gobernar y hacer leyes. No es que en el país no se necesitaran más médicos, sino que contaran con la formación clínica exigida. Al respecto, determinó un currículo y las prácticas como algunos de los requisitos prioritarios para obtener el título. Desafortunadamente, el país no contó con los recursos ni con la estructura que esta reforma exigía y se perdió la oportunidad de iniciar la modernización.

\section{La práctica pedagógica inscrita en la práctica política: el sueño de un rol político-pedagógico del maestro}

En Colombia, la instrucción pública fue una preocupación constante una vez lograda la independencia. Así se muestra muy brevemente en los dos apartados anteriores. Avanzando en el tiempo se indaga sobre el rol social del maestro durante la época del Estado Soberano de Santander (1857-1886) y se encuentra una redimensión de su papel, incluyendo de manera explícita el rol político.

Este nuevo rol puede apreciarse, según Báez, en las siguientes afirmaciones:

[...] los instructores santandereanos pusieron por primera vez en funcionamiento en el estado soberano de Santander, a lo largo de la década de 1870 y hasta 1885 , un sistema pedagógico moderno con orientación social, cimentado en el apoyo de la Misión Alemana, formada 
por un grupo de profesores invitados para que educaran buenos maestros y los guiaran en la adaptación y perfeccionamiento de las pedagogías de Pestalozzi (150).

Para la difusión de esta pedagogía, el Gobierno nacional dispuso la conformación de Sociedades de institutores (artículo 136 del Decreto Orgánico de Instrucción Pública, del primero de noviembre de 1870). Según un estudio realizado por Fonseca, Vera y Arciniegas, en Santander se estableció la Sociedad Didáctica, en la cual los profesores y maestros ejercieron un rol político, tal como puede leerse en El Pestalozziano: "Los infrascritos, profesores en el ramo de la instrucción pública, hemos convenido en establecer un vínculo social bajo la denominación de Sociedad Didáctica" (109). Como toda sociedad del siglo XIx, la Sociedad Didáctica fundó su propio órgano de difusión oficial, llamado El Pestalozziano, con el objetivo de promover el sentido pedagógico de Pestalozzi y brindar aportes a la educación y a la cultura en general (Cansino).

Así mismo, por su composición, la Sociedad Didáctica fue una organización para adquirir conocimientos; sus integrantes se reunían todas las semanas para discutir ideas filosóficas y pedagógicas, desarrollar veladas literarias y dictar conferencias, por turnos rigurosos de sus miembros, sobre temas científicos, culturales y sociales (Fonseca, Vera y Arciniegas 109).

En El Pestalozziano se encuentra que esta sociedad tenía unos reglamentos que hacen referencia a una organización, a la necesidad de tener un órgano de difusión, a las características de sus miembros y a la promesa de la Sociedad Didáctica. En cuanto a los miembros, el señor Barroso introdujo la siguiente proposición que fue aprobada: "La Sociedad Didáctica tendrá tres clases de socios a saber: natos, los maestros de profesión, honorarios, los empleados accidentales del ramo de instrucción pública o privada; corresponsales de los amigos de la instrucción" (Cansino).

¿Qué elementos importantes surgen en esta época en la imagen social del maestro? El pensamiento de la Sociedad Didáctica, sin duda, concibió al maestro como un intelectual al servicio de la educación desde una concepción política. Así lo expresaron en $E l$ Pestalozziano:

[...] seguimos sin embargo una bandera política, consiste aquella en sostener que el principios de que toda legislación i toda forma de gobierno son incompletas, son ineficaces, si la educación y la instrucción de las masas no van a la vanguardia de la lei preparando el camino de la moral i el progreso. (Fonseca, Vera y Arciniegas 109-110)

Y complementa la posición el presidente del Estado Soberano de Santander, Victoriano de Diego Paredes, en 1867, quien en su informe a la Asamblea expresó: "dar instrucción al pueblo significa emanciparlo de la esclavitud, de la ignorancia, de la miseria i de los crímenes, habilitarlo para la ciudadanía, darle bienestar i riqueza" (Paredes 10).

Es decir, que el liberalismo radical concentró sus esfuerzos, en la década de 1870, por lograr separar la acción de la Iglesia en la vida cultural y civil; su intención era moldear el ciudadano ideal, según la concepción del liberalismo. Y para cumplir con este propósito, especificó que

[...] ese ciudadano ideal debía ser el maestro de escuela, el maestro preparado por las escuelas normales que implantaron los gobiernos radicales. El maestro de escuela, sobre todo en la versión masculina, debía ser un individuo con influencia en la vida pública aldeana, es decir, debía estar en capacidad de disputarle la antigua preeminencia al gamonal, al tinterillo y al cura; debía, además, ser un individuo capacitado para la vida asociativa y deliberante; eso significa que debía hacer parte de los círculos de opinión, difusor de las bondades del sistema educativo liberal; también debía ser un modelo de costumbres cívicas, modelo de sobriedad y temperancia tanto en la vida privada como en la vida pública”. (Loaiza 64)

$\mathrm{Al}$ respecto, se puede asumir que las reformas escolares correspondientes a 1870 tuvieron como sujeto central al maestro, pues el liberalismo radical, en su preocupación por separar el poder del Estado del de la Iglesia, intentó...

[...] erigirlo como la figura civil y laica por excelencia que podía relativizar la antigua influencia del cura en la parroquia. Las escuelas normales funcionaron, en todo caso, como dispositivos en la formación de un nuevo tipo de individuo, aleccionado en los deberes como maestro y como ciudadano, como difusor del lenguaje cívico republicano, y apropiado de un método de enseñanza que marcaba distancia con respecto a la tradición cultural de la Iglesia católica. (Loaiza 89)

Es evidente que para los liberales, la escuela primaria, la escuela normal y la universidad fueron los lugares elegidos para el aprendizaje y la difusión de sus ideales. 


\section{La pedagogía activa y la búsqueda de un rol intelectual de maestro para que la nación entrara a la Modernidad}

La Ley Uribe de 1903 fundamentó los dos principios que enmarcarían el saber pedagógico y la educación pública hasta mediados del siglo: de una parte, el énfasis en la función metodológica de la pedagogía, y de otra, el progreso económico como finalidad educativa. En este marco normativo, ya desde inicios del siglo $\mathrm{xx}$, se pensó que la formación del maestro se orientara hacia una práctica investigativa y la experimentación científica en el laboratorio. En la mencionada ley se establece que:

[...] las nociones suficientes no sólo en el orden moral e intelectual, sino también en los principios fundamentales aplicables a la industria, a la agricultura y al comercio $[. .$.$] y que con ellas se formen maestros prácticos,$ más pedagogos que eruditos. (Uribe 99)

Sáenz, Saldarriaga y Ospina afirman que en estos años se llevaron a cabo muchas propuestas, entre ellas, la de un Congreso Pedagógico Nacional:

El Congreso pedagógico nacional, en 1917, el cual hizo especial énfasis en la transformación de las escuelas normales, dentro de los esfuerzos de reforma pedagógica [...] debería incluir el aumento a seis años en el pensum, el incremento en las exigencias de admisión y la introducción de las excursiones escolares, concebidas éstas, a la manera de la escuela activa, como ejercicios de observación del medio natural en contraposición a los métodos verbales y de presentación de objetos y láminas en el salón de clases de la metodología Pestalozziana del plan Zerda. ${ }^{4}(141)$

También afirman Sáenz, Saldarriaga y Ospina, que como fruto de ese congreso realizado en 1919, se fijó un nuevo plan de estudios para las escuelas normales, que rigió desde inicios del año 1920, el cual tenía las siguientes particularidades: a) adopta los principios,

4 La Ley 89, conocida también como el "Plan Zerda", reglamentó jurídica y normativamente la educación y estableció las bases de un sistema nacional educativo sobre el que el Gobierno central tenía la suprema inspección y reglamentación. El Plan Zerda organizó la inspección educativa y las direcciones departamentales de educación; dividió la educación en primaria, secundaria y profesional; y dejó a cargo de la administración departamental la instrucción primaria, y la educación secundaria y superior a cargo del Gobierno nacional. http://ar.answers.yahoo.com/ question/index?qid=20090723133247AAA56gB, 23 feb. 2010. conceptos y prácticas de la pedagogía activa y los saberes experimentales que la sustentaban; $b$ ) se adoptan las nuevas concepciones del funcionamiento de la mente; c) se implementaron las prácticas experimentales del examen escolar, y d) se avanzó en la implementación de los métodos activos de enseñanza. En la Normal Central, la revista pedagógica, incluía traducciones inéditas de principios sicológicos y médicos, y de pedagogos modernos de Europa y Estados Unidos (Sáenz, Saldarriaga y Osipina 145 y ss.).

A partir de 1934 se inicia el periodo de transición entre la antigua formación normalista y la creación de las facultades de educación; aparece la Normal Superior en 1936. La Ley 36 de este año cambió el nombre de Facultad de Ciencias por el de Normal Superior; esta institución, Sáenz, Saldarriaga y Ospina,

[...] se convirtió en la institución por excelencia en el proceso de modernización, pluralización e internacionalización del saber en el país [...] la pedagogía de Ovidio Declory [...] en el campo de lo social llega el determinismo biológico y las teorías evolucionistas [...] se introdujeron los últimos avances del saber, incluyendo la etnología, el marxismo, la pedagogía de John Dewey y el sicoanálisis. (176)

En esta época aparece otro hecho importante en la formación normalista, la creación de las Escuelas Normales Rurales (1934), que según Sáenz, Saldarriaga y Ospina se convierten en

[...] elemento central de la política de cultura aldeana formulada por Luis López de Mesa [...] Las Normales Rurales, dirigidas inicialmente a la formación de maestras, se constituyeron en uno de los instrumentos privilegiados de los gobiernos liberales para implementar sus políticas de modernización, democratización y asistencia social hacia la población campesina. (163)

¿Qué elementos importantes surgen en esta época en la imagen social del maestro? Al respecto, los autores citados asumen que por la circulación y apropiación de saberes modernos, tales como los conceptos de la infancia, de la psiquis, la biología y la medicina, que sustentaban la pedagogía, las Normales fueron modificando el papel del maestro, en la medida en que cambiaron los requisitos de ingreso. Por ejemplo, para pedagogos como Agustín Nieto Caballero y Gabriel Anzola Gómez, el maestro debía ser un experto en métodos activos, es decir, asumir un papel orientado 
más hacia la enseñanza, mientras que para los médicos Miguel Jiménez López y Eduardo Vasco Gutiérrez, debía ser un experimentalista que, en colaboración con el médico, fundamente su práctica en el examen fisiológico y sicológico del alumno, es decir, un funcionario especialmente encargado de controlar; para un tercer grupo, en el cual estuvo el pedagogo Rafael Bernal Jiménez, el maestro debía ser un defensor de la raza. Y a mediados de los años treinta, Jorge Zalamea y Luis López de Mesa enfatizan en la función cultural y sociopolítica del maestro (Sáenz, Saldarriaga y Ospina 156 y ss.).

Así lo expresa también la ficha del maestro utilizada por el Ministerio de Educación para el escalafón del magisterio, en la que ya no se encuentran las exigencias morales del buen católico. Aparece un ideal de maestro activo y funcional para los fines sociales del estado liberal: compañerismo y colaboración, capacidad de adaptación, comprensión y simpatía por la infancia y acción social (Ministerio de Educación Nacional y Misión Alemana). A este perfil se le fueron agregando otras exigencias, como: un espíritu investigativo para vivir actualizado en innovaciones sicológicas y pedagógicas.

El rol social e intelectual del maestro de la época de las Escuelas Normales Superiores gozó de un gran prestigio intelectual, tal como lo expresa Socarrás:

En el periodo de las Escuela Normales Superiores, se vincularon profesores oriundos de España, Alemania, Italia y Francia difundiendo las modernas teorías de las ciencias naturales y sociales (Herrera y Low, 1990, p. 25). De esta manera las tendencias e ideologías que se desarrollaron en Europa se desarrollaron en las escuelas normales.

\section{La contrarreforma a las escuelas normales superiores, el regreso al rol moralizador}

Martha Herrera y Carlos Low afirman que a lo largo de la historia los maestros han sido víctimas de los vaivenes políticos:

[...] en el periodo de la restauración conservadora (19461957) se empezaron a desmontar las reformas y los avances gestados en la república liberal. Los conservadores consideraron las escuelas normales como instrumentos fundamentales de control ideológico, algunas de sus po- líticas consistieron en hacer una purga de liberales en el magisterio y en la dirección de las normales, al tiempo se suspendieron los espacios de reunión de los docentes y se persiguieron los sindicatos. (47)

Con estas medidas se pierde todo el avance en el conocimiento que se había construido durante la República liberal y la contratación de maestros tuvo como criterio la pertenencia al partido conservador, en detrimento del saber y la calidad; era una vinculación por clientelismo político, sin necesidad de exigirles que tuvieran títulos académicos. Un ejemplo de esta tendencia está en las siguientes cifras: en 1931, el 48\% de los maestros urbanos eran diplomados; para 1953, el porcentaje de los maestros con títulos bajó al 40\%; esto trajo como consecuencia lógica la baja de la calidad de la educación. Otra característica de esta época fue la reorientación de la educación normalista, para ponerla al servicio del catolicismo, la patria y la formación de "buenos ciudadanos" (Herrera y Low 47).

El efecto de esta contrarreforma lo expresan Martínez, Noguera y Castro en la siguiente tesis:

[...] entre finales de los años 40 y comienzos de los 60, el campo educativo sufre una transformación radical que afecta tanto sus fines sociales como su estructura y funcionamiento. Esta transformación antes que una continuidad, afianzamiento o afinamiento representa una profunda ruptura, un quiebre en el rumbo que venía siguiendo desde finales del siglo xix. (21)

Para entender mejor las características de la evolución del rol del maestro en la primera mitad del siglo $\mathrm{xx}$, se acude a una investigación de Rodrigo Parra Sandoval, que afirma que los cambios de la educación normalista se dieron en tres sentidos:

[...] un fuerte proceso de privatización impulsado por la fuerte demanda y por la insuficiente respuesta del sector público [...] Otra dirección hacia la que se ha movido la naturaleza de las escuelas normales es la feminización, que ya era notable hacia 1939 cuando el 69\% de las normales eran femeninas en comparación con el 78\% en 1965 [...] el otro fenómeno se refiere al proceso de expansión, en 25 años de, 1939 a 1965, el número de escuelas normales se hizo 1545 veces mayor. (37-38)

¿Qué aspectos de importancia surgen en esta época en cuanto a la imagen social del maestro? El primer análisis que puede hacerse es la pérdida del énfasis del 
rol intelectual, para darle paso nuevamente al rol moralizador; al respecto, Escobar dice:

[...] 1952 a 1957, cierre de la normal superior por decreto del doctor Laureano Gómez y su ministro de educación, quienes consideraron que no será aceptable desde el punto de vista moral, el que los alumnos de diferentes sexos convivieran y trabajaran juntos en las mismas aulas, y en tal virtud determinaron bifurcar la Facultad-Madre de ciencias de la educación enviando a las mujeres al instituto pedagógico de la avenida Chile y los varones a la facultad de Tunja. (14)

Los gobiernos conservadores representaron para el rol social del maestro una ruptura, en el sentido en que vuelve al papel moralizador. Este retroceso significó un golpe para el papel del maestro como intelectual que estaba ayudando a que Colombia entrara a la Modernidad, dándoles a los niños y jóvenes una educación más cualificada.

\section{La tecnología educativa: el maestro como administrador del currículo}

Como antecedentes cercanos a la implementación de la tecnología educativa se pueden citar hechos importantes, como: a) en 1956 se pone en marcha el Primer Plan Quinquenal de Educación, dentro del proceso de transformación de la enseñanza en el país; b) se expide el Decreto 1710 de 1963, en el cual se fijan los objetivos de la educación primaria y se unifica el plan de estudio para todas las escuelas, y c) el Decreto 1955 de este mismo año reorganiza los estudios normalistas, para lo cual se establece un nuevo plan de estudios.

En este decreto se plantea:

[...] una de las necesidades inaplazables es la de acentuar el carácter profesional de la escuela normal para que pueda dar una mayor orientación y formación al magisterio de enseñanza elemental [...] intensificar el estudio de las ciencias y las técnicas pedagógicas con el fin de que el maestro pueda comprender y orientar la conducta del niño y guiarlo en el proceso de aprendizaje.

Martínez, Noguera y Castro declaran que el 25 de noviembre de 1968 se firma un convenio adicional con el Gobierno alemán, para articular una reforma a la enseñanza. Esta misión inicia sus actividades con el diseño y elaboración de materiales didácticos, guías para el maestro (de las cuales se editaron cerca de 300.000 ejemplares, de $1^{\circ}$ a $5^{\circ}$ de primaria), cuyo objetivo era dotar al maestro de un instrumento que le permitiera desarrollar el programa del curso, indicándole la metodología para su enseñanza y sugiriéndole actividades prácticas complementarias, con el fin de alcanzar la deseada mejora cualitativa del proceso enseñanza-aprendizaje (Martínez, Noguera y Castro 64).

En esta etapa, el proceso de enseñanza y aprendizaje estuvo planificado paso a paso. Esto es un ejemplo que ilustra el momento. Lo evaluativo se considera de importancia vital dentro del proceso educativo (Martínez, Noguera y Castro 15) y lo definen como: "una manera de apreciación sistemática del rendimiento de los alumnos, teniendo en cuenta el conocimiento, la habilidad y la comprensión con el mínimo de subjetividad y el máximo de seguridad" (16).

Además de la misión pedagógica alemana, la Organización de Estados Americanos (OEA), en el año de 1968, después de un estudio realizado elaboró un proyecto multinacional con el objetivo de "apoyar a los países en el desarrollo y utilización de la televisión educativa, mediante acciones de capacitación de recursos humanos, dotación de estudios de televisión educativa y otros audiovisuales y producción de material" (Martínez, Noguera y Castro 17).

La Resolución 4785 de 1974 reglamentó una estructura curricular básica no especializada.

El análisis de estas áreas revela nuevamente el énfasis de la cultura humanística sobre la cultura pedagógica o profesional y sobre el área de habilidades y destrezas vocacionales [...] el proceso de formación no resignificó la vana pretensión de un cambio radical en la cultura de la escuela normal, sino el mantenimiento de una organización rígida basada en diferencias jerárquicas que constituían el engranaje del "habitus pedagógico" de los maestros colombianos. (18)

¿Qué características destacadas surgen en esta época en relación con la imagen social del maestro? El brevísimo recorrido por este momento permite concluir que en este tiempo el maestro quedó convertido en un administrador curricular. Se perdió el trabajo pedagógico y aunque hubo el acompañamiento de una misión pedagógica alemana, no se pudo comprender para qué sirve la pedagogía, cuando al maestro se le considera un seguidor de instrucciones. Tezanos lo expresa así: 
[...] el dominio más relevante en el proceso de formación de docentes es el cognitivo, en tanto el maestro debe "saber", "saber cómo" y "saber por qué". Todo está creado desde condiciones previas, el conocimiento es sinónimo de almacenamiento de información, conocer significa informarse, y enseñar significa saber repetir y saber transmitir (57).

En este momento histórico, la pedagogía se limita a una acción instrumental, planificada por otras ciencias. La función del maestro es seguir instrucciones.

\section{Movimiento pedagógico: el maestro, de portador a productor de saber}

La tecnología educativa enajenó al maestro y a la pedagogía. Como reacción a esta situación, en los años ochenta aparece el Movimiento pedagógico; según Mejía, Martínez y Unda:

Es posible reconocer las raíces de este movimiento en la convergencia de diversos factores: por una parte, iniciativas de maestros organizados en pequeños grupos, motivados por la reflexión pedagógica sobre sus prácticas en la escuela; en segundo lugar, actividades de investigación realizadas por intelectuales vinculados a la universidad pública [...] sobre la identidad intelectual del maestro o sobre la enseñanza de las ciencias y el papel de conocimiento en la escuela; un tercer factor tiene que ver con las resistencias a las políticas educativas centradas en el impulso del modelo curricular; y un cuarto factor, los trabajos relacionados con la educación popular. (13)

Como puede apreciarse, el Movimiento pedagógico configura una nueva imagen del maestro; es un movimiento de reflexión sobre su identidad, sobre su práctica; un movimiento de resistencia a las políticas; es, en otras palabras, la creación de una corriente de pensamiento ${ }^{5}$ desde otros presupuestos, distintos a la mirada oficial. Un trabajador de la cultura.

\section{El maestro como trabajador de la educación}

5 Para consolidar este pensamiento pedagógico, se creó la revista Educación y Cultura, en 1984, como una publicación del Centro de Investigaciones Docente (CEID), de la Federación Colombiana de Educadores, Fecode. Es una revista semestral que aborda todas las problemáticas de la educación, y su propósito es representar al maestro como un actor cultural y político, defensor de la democracia.
Con esta visión, el maestro es despojado de su función formadora y se convierte en un administrador. El planteamiento que lo orienta es que la educación es un instrumento de los intereses de la economía y las políticas nacionales que siguen las tendencias a nivel internacional, hecho que se ha agudizado a causa de la globalización. Actualmente no se enseña, se instruye, y en consecuencia se han sustituido a los maestros por profesionales de cualquier rama, sin tener en cuenta lo pedagógico.

Por esta razón, las facultades de educación hacen esfuerzos por recuperar su función en la formación de profesionales de la educación capaces de comprender el contexto cultural en el cual laboran, con el fin de buscar la transformación de los mismos en beneficio de la colectividad. Considerando, como afirma Martínez Boom (1), que "la educación necesita ponerse a la altura de las profundas transformaciones y cambios que en la sociedad actual se están produciendo, muy especialmente en el área de generación de conocimiento", la formación de los maestros es imperativa para responder a las expectativas y a las exigencias actuales.

A manera de conclusión se puede afirmar que la globalización ha llevado a elevar la competitividad de los individuos y de las empresas, los cuales deben responder a las nuevas exigencias, entre las cuales la interconectividad es fundamental.

Si la competitividad no se incrementa es muy complicado que se pueda vincular con la globalización, y las instituciones educativas se han de convertir en instancias generadoras del desarrollo de las potencialidades, es decir, en generadoras de conocimiento. En esta perspectiva, el Estado debe ocuparse de garantizar niveles altos de eficacia y, a la vez, de eficiencia del sistema, no solo educativo sino productivo. Así el conocimiento vuelve a la premisa de todas las épocas: quien tiene el saber tiene el poder.

\section{Referencias}

Álvarez, Alejandro. "Y la escuela se hizo necesaria." En búsqueda del sentido actual de la escuela. Bogotá: Mesa Editorial Magisterio, 1995. Impreso.

Báez, Myriam. Las Escuelas Normales y el cambio educativo en los Estados Unidos de Colombia en el periodo radical de 1870-1886. Tunja: Universidad Pedagógica y Tecnológica de Colombia, 2004. Impreso.

Bronoswky, Jacob. Ascenso del hombre. Bogotá: Fondo Educativo Interamericano, 1979. Impreso.

Calonje, Patricia. "El círculo del tiempo y los maestros." Educación y Cultura No. 7 (1986): 12-19. Impreso. 
Cansino, Sandalio. "La sociedad didáctica de Santander." El Pestalozziano 8 de septiembre (1876): 10. Impreso.

Dewey, Jhon. Democracia y Educación. Buenos Aires: Losada, 1967. Impreso.

Escobar, Gustavo. "Notas históricas de las Escuelas Normales y las facultades de educación en Colombia." Educación y Cultura (1990): 10-18. Impreso.

Fonseca, Sandra, Carolina Vera y Fredy Arciniégas. "La Sociedad Didáctica de Santander: una asociación político pedagógica para difundir la reforma instruccional." Rastros Rostros (2009): 107-117. Impreso.

Herrera, Martha y Low, Carlos. "Historia de las Escuelas Normales en Colombia". Educación y Cultura (1990): 40-46. Impreso

Lechner, Norbert. ¿Qué significa hacer política? Santiago de Chile: Desco, 1982. Impreso.

Loaiza, Gilberto. "El maestro de la escuela o el ideal liberal de ciudadano en la reforma educativa de 1870". Historia Crítica No. 34. Junio - diciembre (2007): 62-91. Impreso.

Martínez, Alberto, Noguera, Carlos y Castro, Jorge. Currículo y modernización. Bogotá: Cooperativa Editorial Magisterio, 2003. Impreso.

Martínez Boom, Alberto. De la escuela expansiva a la escuela competitiva. Dos modos de modernización en América Latina. Barcelona: Editorial Antropos, 2004. Impreso.

Mejía, Marco Raúl, Martínez, Alberto y Unda, Pilar. El itinerario del maestro de portador a productor de saber. Bogotá: Universidad Pedagógica Nacional, 2002. Impreso.

Ministerio de Educación Nacional y Misión Alemana. "Guías para los maestros de la enseñanza primaria." Guías para la enseñanzaprimaria. Bogotá:Imprenta Nacional, 1975. Impreso.
Ministerio de Instrucción Pública. Decreto 595 de 1886. Bogotá, 1886. Web. <http://www.mineducacion.gov.co/1621/ articles-102385_archivo_pdf.pdf>

Obispo de Pamplona. Pastoral del obispo de Pamplona. Pamplona, Colombia, 1858. 50. Impreso.

Paredes, Victoriano de Diego. "Informe a la Asamblea del Estado Soberano de Santander." De gestión educativa. Bucaramanga: Imprenta departamental, 1867. Impreso.

Parra Sandoval, Rodrigo. Los maestros colombianos. Bogotá: Plaza y Janés, 1986. Impreso.

Pineda Martínez, María. Redes pedagógicas: constitución del maestro como sujeto político. Bogotá: Magisterio, 2008. Impreso.

Sáenz, Javier, Saldarriaga, Óscar y Ospina, Armando. Mirar la infancia: pedagogía moral y Modernidad en Colombia, 1903-1946. Bogotá: Colciencias y Uniandes, 1997. 132187. Impreso.

Socarrás, José. El perfil social de los maestros. Bogotá: Edit. Martha Hernández, 1986. Impreso.

Tezanos, Aracely de. Maestros artesanos intelectuales. Un estudio crítico sobre su formación. Bogotá: Universidad Pedagógica Nacional, 1986. Impreso.

Uribe, Antonio José. "Instrucción pública: disposiciones vigentes.” Ley Uribe 103. Bogotá: Imprenta Nacional, 1927. Impreso.

Zuluaga, Olga Lucía. "La institucionalidad de la pedagogía en Colombia.” Educación y Pedagogía. (1984): 91-125. Impreso. 